\title{
$7 \mathrm{~T}$ MRI에서의 다양한 RF 코일에 대한 $B_{1}^{+}$비교
}

\section{$B_{1}^{+}$Comparison for Different RF Coils at $7 \mathrm{~T}$ MRI}

\author{
김 홍 준·유 형 석* \\ Hongjoon $\mathrm{Kim} \cdot$ Hyoungsuk Yoo* \\ 요 약
}

정 자장 $\left(B_{0}\right)$ 의 세기가 $7 \mathrm{~T}$ (Tesla) 고자기장 MRI(Magnetic Resonance Imaging) 시스템은 정 자장의 세기가 1.5 $\mathrm{T}$ 또는 $3 \mathrm{~T}$ MRI 시스템에 비하여 인가된 RF(Radio Frequency) 필드의 높은 불균질성을 보여준다. 이러한 문제점 를 극복하기 위한 한 방법으로써, 관심 영역에서의 RF 자장이 균일하도록 RF 코일의 각 요소로 들어가는 최적 화된 전류의 크기와 위상 값을 얻기 위해서 convex 최적화 방법이 사용된다. 이러한 방법을 $7 \mathrm{~T} \mathrm{MRI} \mathrm{시스템에}$ 다양한 $\mathrm{RF}$ 코일에 적용하여 각각의 $B_{1}^{+}$필드 값을 비교하여 그 성능을 파악하였다.

\section{Abstract}

This paper demonstrates the use of the convex optimization to localize the transverse magnetic $B_{1}^{+}$field in regions of interest for recently proposed multi-sectioned alternating impedance coils and the traditional transmission line coil. An approach based on different axial slices to identical RF coils except upper stripline structure is investigated. Electromagnetic simulation results are compared for RF coils and discussed in detail at 7.0 $\mathrm{T}$.

Key words : Magnetic Resonance Imaging(MRI), Convex Optimization, Transmission Line Coil, RF $B_{1}^{+}$Field, Parallel Excitation, High Field MRI

\section{I. 서 론}

초고자기장 MRI(Magnetic Resonance Imaging) 시 스템(4 T 이상)은 우수한 신호 대 잡음비(SNR)를 가 지고 있으며, 현대 의학에서 진단과 분석을 위한 중 요한 도구로 사용될 가능성이 높아, 현재 많은 연구 가 이루어지고 있다 ${ }^{[1] \sim[3]}$. 그러나 초고 자기장에서는 전자기파의 특성상 $\mathrm{RF}$ 코일에 의한 자장이 불균일 하여 관심 영역(region of interest) 내에서 균일한 영 상을 획득하기가 힘들다. 최근에는 멀티 채널을 이
용한 마이크로스트립의 전송선 형태의 TEM(Transverse Electromagnetic) 코일이 많이 연구되어지고 있 다. 이러한 멀티 TEM 코일의 장점은 각 코일 소자에 여기되는 전류의 위상과 크기를 조절함으로써 독립 적으로 조절하여 균일한 자장을 얻기에 상당히 유리 하다.

뇌의 전체적인 영역보다 뇌질환에 해당하는 관심 영역을 자세히 보기 위해서 각 코일 소자들의 파라 미터들은 convex 최적 방법 ${ }^{[4]}$ 에 의해서 최적화 할 수 있다. 기존의 연구에서는 일반적인 TEM 코일을 이

\footnotetext{
「이 논문은 2012년 울산대학교 연구비에 의하여 연구되었음. 경북대학교 전기공학과(Department of Electrical Engineering, IT College, Kyungpook National University) *울산대학교 전기공학부 의공학과(Department of Biomedical Engineering, School of Electrical Engineering, University of Ulsan)

- Manuscript received June 12, 2012 ; Revised July 2, 2012 ; Accepted July 3, 2012. (ID No. 20120612-069)

· Corresponding Author : Hyoungsuk Yoo (e-mail : hsyoo@ulsan.ac.kr)
} 
용한 convex 최적 기법이 사용되었지만, 본 논문에 서는 다양한 7 T MRI 시스템에서 사용 가능한 변형 된 TEM 코일에 16 채널을 이용하였다.

이러한 방법을 입증하기 위하여 7 T MRI 시스템 에 $\mathrm{RF}$ 코일의 공진 주파수가 $300 \mathrm{MHz}$ 를 가지는 세 가지 형태의 다채널 전송 선로 코일이 인체 두상 모 형과 함께 모델링되었으며, 이 코일에 의하여 자장 이 얻어진다. 본 논문에서는 인체 모형의 중심 영역 부분을 세 가지 코일에 인체 모형의 전체적인 위치 를 다양하게 적용하여 각각 코일의 장단점을 비교 분석하였다.

\section{П. 방 법}

세 가지 다양한 코일 소자의 자장 분포는 FDTD (Finite Difference Time Domain) 방법을 이용하는 REMCOM사의 XFDTD 시뮬레이션을 이용하여 계산 하였다. 7 T MRI 시스템의 공진 주파수인 $300 \mathrm{MHz}$ 단일 주파수를 사용하였다. 그림 1은 TEM 코일의 옆 모양과 원통형 인체 모형이며, 다양한 슬라이스 에서 $B_{1}^{+}$필드가 계산됨을 보여주고 있다. $7 \mathrm{~T} \mathrm{MRI}$ 시스템에서 사용되는 특성 파라미터를 이용하였다. 슬라이스의 간격은 $0.254 \mathrm{~cm}$ 이며, 슬라이스 0 은 인 체 모형의 중심을 나타낸다. 인체 두상을 원통형 균 일 물질로 된 모형을 이용하여 각각의 슬라이스를 동일한 조건에서 비교하여 세 가지 다른 코일의 특 성을 나타내고자 한다. 실제 다른 논문 ${ }^{[1]}\left[{ }^{33]}\right.$ 에서는 heterogenous한 인체 모형을 사용하여 그 중심 슬라 이스에서만 특성을 파악하는데, 본 논문에서는 convex 최적화 기법을 모든 슬라이스에 적용하여 그 차 이점을 파악한다.

\section{2-1 Convex Formulation}

세 가지의 코일을 비교하기 위해서 특정 대상 영 역에서는 신호의 크기를 증가시키고, 특정 대상 영 역을 제외한 영역 ${ }^{[4]}$ 에서는 신호의 크기를 감소시키 기 위해서 convex 최적화 방법을 사용하였다. 기본 적인 convex formulation은 다음과 같이 나타낼 수 있 으며, 구체적인 내용은 참고문헌 [4], [5]에 있다.

minimize $\max \left|B_{1, s}^{+} w\right|, s \in$ Suppression Region subject to $B_{1, c}^{+} w=1, c \in$ Center of Target

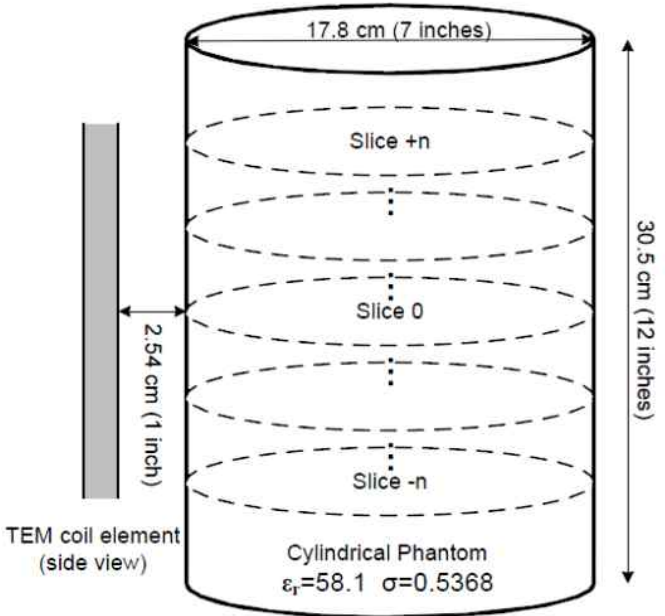

그림 1. TEM 코일과 원통형 모형, $B_{1}^{+}$필드가 계산 된 축방향의 슬라이스를 표현한 모식도

Fig. 1. TEM coil element, the cylindrical phantom, and the axial slices where $B_{1}^{+}$fields are calculated.

$B_{1, s}^{+}, B_{1, c}^{+}$는 각각 특정 대상 영역 제외한 영역에 서의 자장, 특정 대상 영역 중심에서의 자장을 각각 나타낸다 ${ }^{[5]}$. 기존의 논문 ${ }^{[5]}$ 은 convex 최적화 기법을 일반적인 RF 코일의 중심 슬라이스에 대해서만 분 석을 하였으며, 본 논문에서는 convex 최적화 기법 을 다양한 코일과 인체 모형의 전 슬라이스 영역에 대해 자세하게 비교 분석하였다.

\section{2-2 세 가지 종류의 TEM 코일}

이전 논문에서는 일반적인 TEM 코일 형태에 대 해서만 필드의 균질성을 다루었다. ${ }^{[4]}$ 본 논문에서는 그림 2에서 보는 것처럼 세 가지의 TEM 코일에 convex 최적 기법을 적용하였다. 그림 2(a)는 TEM 코일 의 옆 모습을 보이며, 세 가지 코일 모두 동일한 형 태이다.

그림 2(b)는 일반적인 코일의 모습이며, 그림 2(c) 와 2(d) 7 section, 3 section 형태의 TEM 코일의 모습 이다. 코일의 윗 모양을 달리하여 특성 임피던스를 변화하여 코일의 필드 분포가 달라지게 된다. 굵은 라인이 상대적으로 가는 라인보다 작은 임피던스를 가진다. 따라서 높은 임피던스를 가지는 가는 부분 이 더 큰 전류 밀도를 가지며, 이들의 변화를 통하여 인체 모형에 전달되는 전자기장을 계산하였다. 실제 로 MRI 시스템은 근거리 자장으므로 모형과의 coupling 때문에 전자기학적으로 유추하기가 힘들기 때 


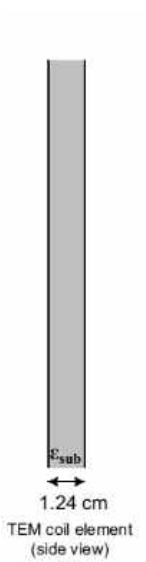

(a)
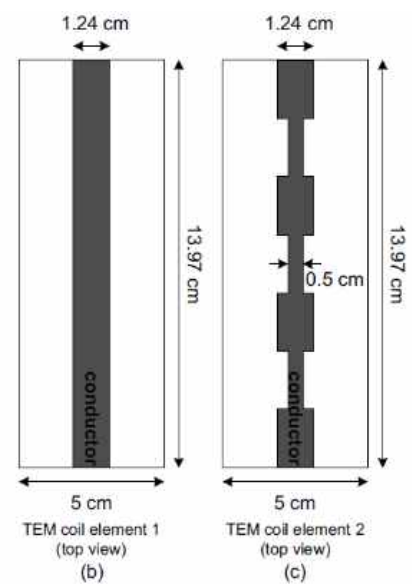

(c)

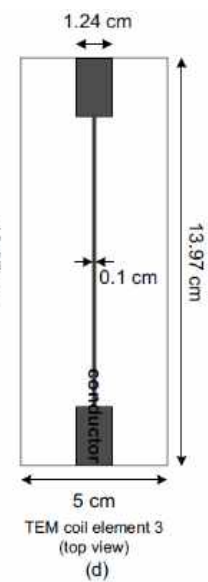

(d)

(a) TEM 코일 소자 옆면, (b) 일반적인 TEM 코일 소자 윗면, (c) 7 section TEM 코일 소자 윗면, (d) 3 section TEM 코일 소자 윗면

(a) TEM coil element side view, (b) general TEM coil element top view, (c) 7 section TEM coil element top view, (d) 3 section TEM coil element top view

그림 2. $7 \mathrm{~T} \mathrm{MRI에서} \mathrm{사용되는} \mathrm{세} \mathrm{가지의} \mathrm{다른} \mathrm{형태}$ 를 가진 각각의 $\mathrm{TEM}$ 코일 소자

Fig. 2. Three different TEM coil elements for $7 \mathrm{~T}$ MRI system.

문에 많은 시뮬레이션이 필요하다.

7 section과 3 section은 그림 2처럼 서로 다른 윗 면의 구조를 가지며, 높이 $1.24 \mathrm{~cm}$, 길이 $13.97 \mathrm{~cm}$, Teflon을 substrate(유전율 2.08)를 가진다. 윗면의 도 체는 기본적으로 $1.24 \mathrm{~cm}$ 넓이를 가지며, 7 section, 3 section 코일은 각각 $0.5 \mathrm{~cm}, 0.1 \mathrm{~cm}$ 의 gauge를 가 진다. 각각의 코일은 약 $300 \mathrm{MHz}(7 \mathrm{~T}, 297 \mathrm{MHz})$ 의 공진 주파수를 가지며, $50 \Omega$ 동축 케이블에 매칭되 도록 모델링하였다.

\section{2-3 Simulation Result}

그림 4는 세 가지 코일의 다양한 축 방향에 대한 슬라이스의 해당하는 $B_{1}^{+}$필드 값을 보여주고 있다. 관심 영역은 중심부위이며, 기준 슬라이스 0 에서 5.1 $\mathrm{cm}$ 떨어진 슬라이스는 \pm 20 이며, \pm 40 은 $10.2 \mathrm{~cm}$ 만큼 떨어진 슬라이스이다. 결과에서 보는 것처럼 $3 \mathrm{sec}-$ tioin TEM 코일이 중심 부위에서 가장 좋은 필드값 을 나타내고 있으며, 슬라이스 $\pm 27(14 \mathrm{~cm})$ 이상 떨어 지게 되면 일반적인 TEM 코일이 가장 좋음을 나타 낸다. 자세한 비교를 하기 위해 모든 슬라이스에 해 당하는 $B_{1}^{+}$값은 그림 5 에 잘 나타나 있다. 기본적인

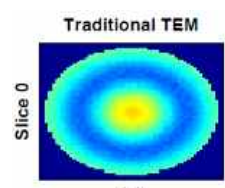

(a)
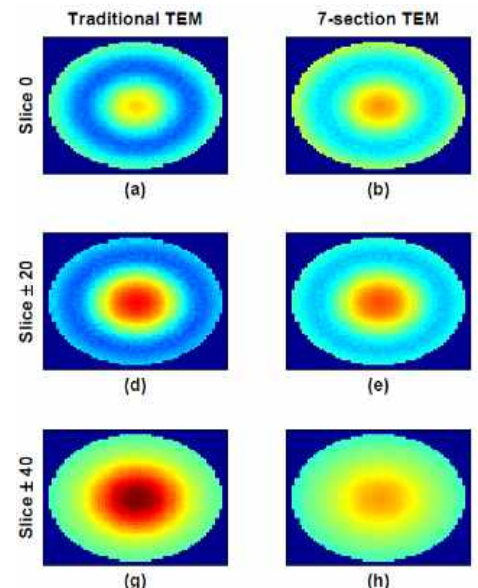

(b)

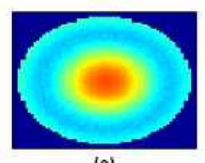

(e)

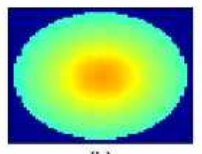

(h)
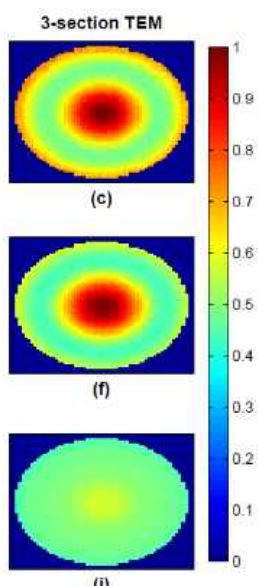

그림 4. 다양한 슬라이스에서의 관심 영역이 가운데 일 때의 16 채널 $B_{1}^{+}$필드 분포. 슬라이스 0 ((a), (b), (c)), 슬라이스 $\pm 20((\mathrm{~d}),(\mathrm{e}),(\mathrm{f}))$, 슬라 이스 $\pm 40((\mathrm{~g}),(\mathrm{h}),(\mathrm{i}))$ 그리고 일반적인 TEM 코일((a), (d), (g)), 7-section TEM 코일((b), (e), (h)), 3-section TEM 코일((c), (f), (i)).

Fig. 4. The $B_{1}^{+}$profiles of 16 channel simulations in the different slices when the ROI is at the center. Slice $0((a),(b),(c))$, Slice $\pm 20((d),(e),(f))$, and Slice $\pm 40((\mathrm{~g})$, (h), (i)) are used for the traditional TEM coil((a), (d), (g)), the 7-section TEM coil((b), (e), (h)), the 3-section TEM coil ((c), (f), (i)).

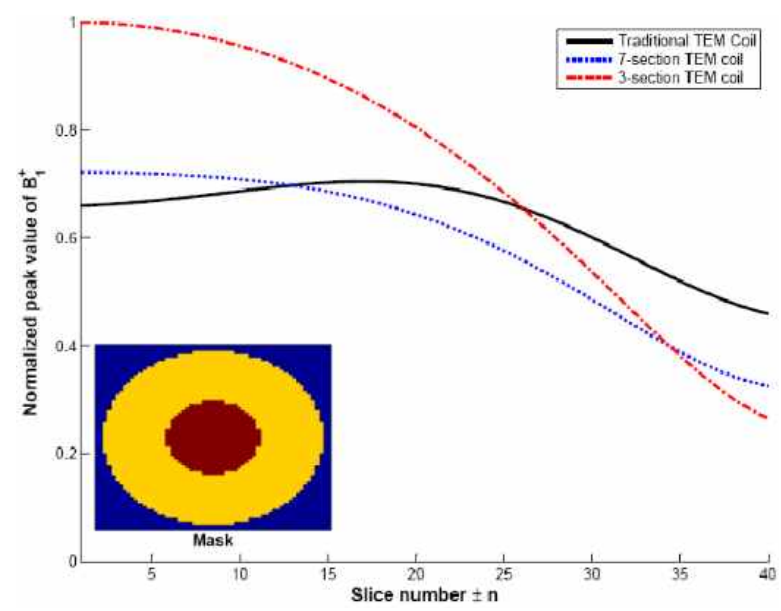

그림 5. 규격화된 $B_{1}^{+}$의 최고점 값과 슬라이스 번호 에 따른 비교값(관심 영역은 모델의 가운데)

Fig. 5. Normalized peak value of $B_{1}^{+}$vs. slice number $\pm \mathrm{n}$ when the ROIs are off the center.

$\mathrm{TEM}$ 코일은 중심 슬라이스에서 멀어짐에 따라 가 장 완만한 변화를 보이고 있으며, 3 section TEM 코 일이 가장 급격한 변화를 보인다. 7 section TEM 코 
일은 그 중간 정도이다. 이것은 각 코일의 특성 임피 던스의 변화 값과도 유사함을 그림 5 에서 확인할 수 있다. 모든 시뮬레이션 값은 가장 큰 값에 정규화되 어 있다.

\section{III. 결 론}

고령화 사회로 진입함에 따라 많은 뇌질환이 야 기되고 있으며, 정확한 진단을 위해 높은 신호 대 잡 임비를 가진 고자장 MRI 시스템이 중요한 도구로 사용되고 있다. 특히 병령 영상 이득을 가진 다채널 $\mathrm{RF}$ 코일이 중요한 요소이며, 그 디자인 기술 또한 중요하다. 좋은 코일의 하나의 지표로써 convex 최 적화에 우수한 코일을 비교 분석하기 위해 본 논문 에서는 일반적인 코일과 7 section, 3 section 코일이 $7 \mathrm{~T}$ MRI에서 비교 분석되었다. 고해상도 MRI 시스 템으로 갈수록 점차 필드의 비균질성 문제가 대두되 며, 뇌질환으로 의심되는 국소적인 부분을 좀 더 정 확하게 판단할 필요성을 고려할 때 핵심 기술인 코 일의 우수성을 검증하기 위해서 이러한 분석은 반드 시 필요하며, 고자장 MRI 시스템에서 자장의 균질 도 판단에 매우 유용할 것으로 기대된다.

\section{참 고 문 헌}

[1] J. T. Vaughan, M. Garwood, C. M. Collins, W. Liu, L. Delabarre, G. Adriany, P. Andersen, H. Merkle, R. Goebel, M. B. Smith, and K. Ugurbil, "7T vs 4$\mathrm{T}$ : RF power, homogeneity, and signal-to-noise comparison in head images", Magn Reson Med, vol. 46, no. 1, pp. 24-30, Jul. 2001.

[2] J. T. Vaughan, L. DelaBarre, C. Snyder, J. Tian, C. Akgun, D. Shrivastava, W. Liu, C. Olson, G. Adriany, J. Strupp, P. Andersen, A. Gopinath, P. van de Moortele, M. Garwood, and K. Ugurbil, "9.4T human MRI: Preliminary results", Magn Reson Med, vol. 56, no. 6, pp. 1274-1282, Dec. 2006.

[3] J. Vaughan, "RF Coil for Imaging System", U.S. patent 6,633:161, 2003.

[4] C. Olson, H. Yoo, L. Delabarre, J. T. Vaughan, and A. Gopinath, "RF $B_{1}$ field localizations through convex optimization", Microwave and Optical Technology Letters, vol. 54, pp. 31-37, Jan. 2011.

[5] 김홍준, 손혁우, 조영기, 유형석, "고자장 MRI에 서의 영상 영역에 대한 $B_{1}^{+}$균질성", 한국전자파 학회논문지, 23(1), pp, 96-100, 2012년 1월. 